\title{
Association among blood pressure control in elderly patients with hypertension, left atrial structure and function and new-onset atrial fibrillation: a prospective 2-year study in 234 patients
}

\author{
Takatomo Watanabe ${ }^{1}$, Masanori Kawasaki ${ }^{1}$, Ryuhei Tanaka ${ }^{2}$, Koji Ono ${ }^{2}$, Kazuhiko Nishigaki ${ }^{1}$, \\ Genzou Takemura ${ }^{1}$, Masazumi Arai ${ }^{2}$, Toshiyuki Noda ${ }^{2}$, Sachiro Watanabe ${ }^{2}$ and Shinya Minatoguchi ${ }^{1}$
}

We assessed the hypothesis that blood pressure (BP)-lowering therapy has a beneficial effect on left atrial (LA) structure and function and may decrease the incidence of new-onset atrial fibrillation (AF) in elderly patients with hypertension (HTN). We divided 234 subjects $\geqslant 65$ years old into four groups based on mean office BP achieved: a normotensive group ( $n=71$ ), a HTN group with good BP control $(n=72)$, a HTN group with poor BP control $(n=41)$ and a HTN group with moderate BP control $(n=50)$. LA volume, emptying function (EF), strain and strain rate (SR) were measured by speckle tracking echocardiography. LA volume, EF, strain and SR in the HTN group with good BP control were better preserved than those parameters in the HTN group with poor BP control. The incidence of new-onset AF during 2 years was significantly higher in the HTN group with poor BP control (hazard ratio: 7.015; 95\% confidence interval: $2.433-20.22 ; \boldsymbol{P}<0.001$ ). In multivariate Cox regression analysis that included the difference in echocardiographic parameters between baseline and follow-up, both age and being in the HTN group with poor BP control were independent predictors of new-onset AF. In multivariate Cox regression analysis that included only parameters at baseline, ratio of the peak early transmitral flow velocity (E) to the peak early myocardial tissue velocity $\left(E / e^{\prime}\right)$ was an independent predictor of new-onset AF. The incidence of new-onset AF depended on the long-term level of BP control rather than short-term changes in LA structure and function. Poor BP control increased the risk of new-onset AF in elderly patients with HTN.

Hypertension Research (2013) 36, 799-806; doi:10.1038/hr.2013.25; published online 4 April 2013

Keywords: atrial fibrillation; atrial function; echocardiography

\section{INTRODUCTION}

Hypertension (HTN) is the most important risk factor for atrial fibrillation (AF) ${ }^{1-3}$ HTN causes pressure overload in the left ventricle and results in left ventricular (LV) hypertrophy. It also increases LV stiffness and diastolic dysfunction, both of which increase with age. ${ }^{4}$ These changes increase the load on the left atrium (LA) and induce the LA remodeling that is associated with $\mathrm{AF}$. AF increases the risk of cardiovascular morbidity and mortality. ${ }^{5}$ Increased LV mass, LA enlargement and dysfunction due to HTN have been identified as independent determinants of new-onset AF. ${ }^{6,7}$ However, there are very few studies that have examined the relationship between blood pressure (BP) level achieved and the incidence of new-onset AF in elderly patients with HTN. In addition, few studies have focused on the relationship between LA structure and function and the incidence of AF.

Recently, the development of echocardiographic technology that includes a feature-tracking method has allowed for the routine evaluation of LA volume and function. ${ }^{8}$ Using this technology, we recently reported that pitavastatin therapy prevented new-onset AF in 220 elderly patients with HTN. ${ }^{9}$ The incidence of new-onset AF was relatively lower than expected because the BP levels were adequately controlled. ${ }^{9}$

Thus, the aim of the present study was to evaluate the relationship between the BP achieved, the cardiac structure and function and the incidence of new-onset AF in elderly patients with HTN.

\section{METHODS}

Subjects and study protocol

This was a nonrandomized prospective study to evaluate the relationship between the BP achieved, cardiac structure and function and the incidence of new-onset AF in the elderly patients with HTN. First, we recruited 380 patients $\geqslant 65$ years old with HTN from the outpatient department of our institution. Patients underwent clinical assessment that included an evaluation of their symptoms and physical condition before enrollment. All patients underwent 
an ECG every month for 2 years before enrollment. All patients who had palpitations and/or symptoms of arrhythmia underwent both an ECG and Holter ECG to determine whether AF was the cause of their symptoms. Patients who had no history of AF were defined as those who had no evidence of AF confirmed by a monthly ECG and clinical assessment for 2 years before enrollment. Exclusion criteria were secondary HTN, atrial arrhythmias, systolic dysfunction (left ventricular ejection fraction $<50 \%$ ), current treatment for congestive heart failure or myocardial infarction or stroke within the past 6 months, moderate to severe mitral valvular disease, severe aortic valvular disease, aortic dissection or aneurysm, renal insufficiency (serum creatinine $>2 \mathrm{mg} \mathrm{dl}^{-1}$ ), mental disorders and severe noncardiovascular disease (for example, cancer or liver cirrhosis). We classified the patients based on their BP control level into three groups: (1) a group with good BP control (systolic BP $<130$ and diastolic BP mm Hg), (2) a group with moderate BP control (systolic BP $\geqslant 130$ but $<140$ and diastolic BP $<90 \mathrm{~mm} \mathrm{Hg}$, or systolic BP $<140$ and diastolic $\mathrm{BP} \geqslant 80$ but $<90 \mathrm{~mm} \mathrm{Hg}$ ) and (3) a group with poor BP control (systolic BP $\geqslant 140$ or diastolic BP $\geqslant 90 \mathrm{~mm} \mathrm{Hg}$; Figure 1). We excluded 60 patients with HTN because of the exclusion criteria and 128 patients because their BP control levels were not constant and they would have been classified into more than one of the three groups over the previous 2 years. The final study group included 192 patients with HTN who were treated with antihypertensive drugs, with BP control level belonging to just one of the three groups throughout the past 2 years (good control, $n=85$; moderate control, $n=64$; poor control, $n=43$ ). We also enrolled 73 normotensive patients $\geqslant 65$ years old who visited our outpatient department monthly to serve as a normotensive control group. These patients had diabetes mellitus $(n=11)$, dyslipidemia $(n=30)$, coronary artery disease $(n=13)$, peripheral artery stenosis $(n=15)$ or chronic obstructive pulmonary disease $(n=8)$, and some patients had more than two diseases (Figure 1). We followed all 265 patients (192 patients with HTN and 73 normotensive patients) for 2 years without any change in antihypertensive therapy unless the systolic BP continued to be $>140 \mathrm{~mm} \mathrm{Hg}$ or the diastolic BP $>90 \mathrm{~mm} \mathrm{Hg}$ for 3 months. In a previous meta-analysis, the risk of $\mathrm{AF}$ was $17.4 \%$ within 6 months in control with risk factors for AF such as coronary heart disease. ${ }^{10}$ Another meta-analysis reported that the risk of AF was $12.4 \%$ within 3 months in control with risk factors for $\mathrm{AF}^{11}$ To the best of our knowledge, there has been no report regarding the risk of AF in elderly patients with HTN. Therefore, we hypothesized that the risk of developing $\mathrm{AF}$ was $10 \%$ within 2 years, referring to the previous two meta-analyses to determine the number of the enrolled patients. BP was measured every month after registration. According to the guideline proposed by the Japanese Society of Hypertension, two consecutive BP measurements were taken from each patient in a sitting position at the outpatient department. ${ }^{12}$ The ethics committee of our institution approved the present study and informed consent was obtained from all patients before enrollment.

\section{Echocardiography}

Transthoracic echocardiography was performed at baseline and after 2 years using an ACUSON sequoia 512 (Siemens, Mountain View, CA, USA)

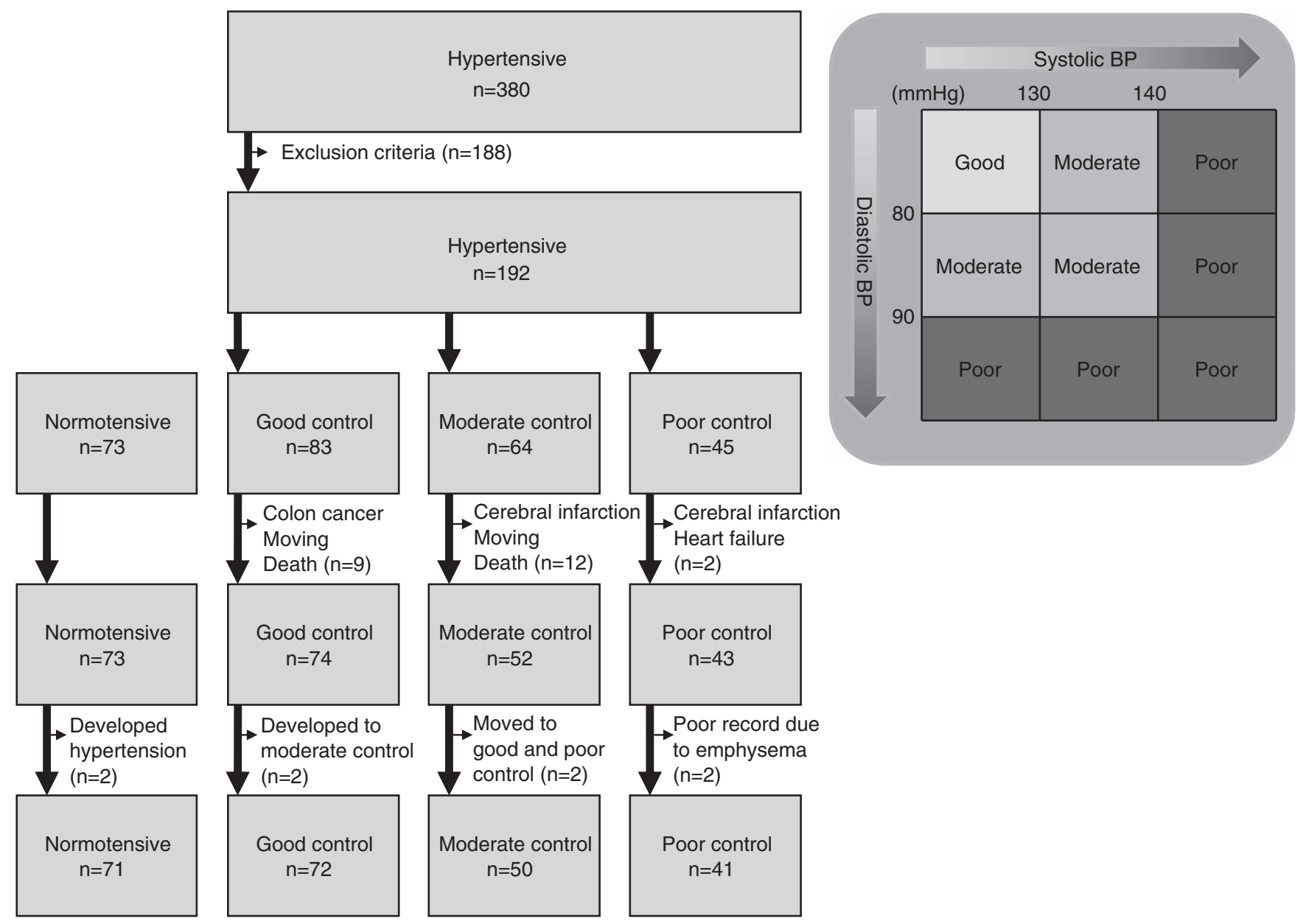

Figure 1 Study flowchart and definitions of hypertension groups. BP, blood pressure. A full color version of this figure is available at the Hypertension Research journal online. 
ultrasound system with a transducer at $4 \mathrm{~V} 1 \mathrm{c}(1.5-4.25 \mathrm{MHz})$. LA volumes were measured during a single cardiac cycle by Velocity Vector Imaging (VVI; Siemens) with feature-tracking echocardiography using online software (Syngo Velocity Vector Imaging, Siemens). The reliability and the reproducibility of the feature-tracking echocardiographic method for the quantification of LA volume (LAV) and function have been established in previous studies. ${ }^{8,9}$ Maximum LAV, minimum LAV and LAV just before atrial contraction were obtained from the apical four-chamber view with a frame rate of 55 to 60 frames $^{-1}$ using Simpson's method. LA total emptying function (EF), passive EF and active EF were calculated to evaluate phasic and global LA function and were defined as (maximum LAV-minimum LAV)/maximum $\mathrm{LAV} \times 100 ; \quad$ (maximum $\quad \mathrm{LAV}-$ pre-atrial contraction $\mathrm{LAV}$ )/maximum $\mathrm{LAV} \times 100$; and (pre-atrial contraction LAV-minimum LAV)/pre-atrial contraction LAV $\times 100$, respectively. LA peak strain rate (SR) during systole, early diastole and atrial contraction were also obtained from the LA mid-septal and mid-lateral walls. LA peak strain was obtained from the average of LA mid-septal and mid-lateral wall strain. Conventional echocardiographic parameters were measured according to standard echocardiographic methods. ${ }^{13}$ The ratio of early diastolic transmitral inflow velocity to annular tissue velocity $\left(\mathrm{E} / \mathrm{e}^{\prime}\right)$ was assessed as an index of diastolic function. LA volumes and functions were evaluated only during sinus rhythm even in the patients who had new-onset AF

\section{Determination of incident AF}

Patients were seen at the outpatient department every month during the follow-up period and an ECG was obtained every month. Transthoracic echocardiography was performed at baseline and after 2 years in all patients. All patients who had palpitations and/or any symptoms of arrhythmia during the follow-up period underwent both ECG and Holter ECG monitoring to confirm or exclude new-onset AF in addition to routine monthly ECG. This determination was applied to most of the previous studies that included AF as an end point. ${ }^{9-11}$ The development of AF was defined as the month when ECG or Holter ECG confirmed the presence of AF.

\section{Reproducibility and reliability of LAV and LAEF by the VVI method}

In our previous study, we reported that the interobserver correlation coefficient and relative differences in maximum LAV, minimum LAV and LA total EF measured by VVI were 0.98 and $0.94 \pm 6.8 \%, 0.99$ and $8.0 \pm 11.0 \%$ and 0.99 and $2.2 \pm 15.9 \%$, respectively. ${ }^{7}$ The intraobserver correlation coefficient and relative differences in those parameters were 0.98 and $2.6 \pm 6.2 \%, 0.98$ and $8.1 \pm 11.6 \%$ and 0.90 and $4.0 \pm 12.4 \%$, respectively. ${ }^{7}$

\section{Statistical analyses}

The data are expressed as the mean \pm 1 s.d. Categorical data were summarized as percentages and compared using the $\chi^{2}$ test. Comparison of echocardiographic parameters between baseline and follow-up in each group were performed by a paired $t$-test. Comparisons of parameters among the four groups were performed by two-way analysis of variance followed by a Bonferroni test for post hoc comparisons. Survival curves were plotted by the Kaplan-Meier method and hazard ratios were calculated by univariate Cox regression analysis. Multivariate Cox regression analysis was performed to determine the independent predictors of new-onset AF. All statistical analyses were performed using Stat View version 5.0 (SAS Institution, Cary, NC, USA). A $P$-value of $<0.05$ was considered to be significant.

\section{RESULTS}

Follow-up of patients and their baseline characteristics

Of the 265 patients, 23 were lost to follow-up for 2 years because of colon cancer $(n=1)$, ileus $(n=1)$, subarachnoidal hemorrhage $(n=1)$, death from pneumonia $(n=1)$, bone fracture $(n=4)$, relocation $(n=3)$, dementia $(n=4)$, sudden death $(n=2)$, brain injury $(n=1)$, asthma $(n=1)$, death from congestive heart failure $(n=1)$, cerebral infarction $(n=2)$ and unknown $(n=1)$. The 2-year follow-up data were obtained in 242 patients (Figure 1). There was no significant difference in major cardiovascular events (myocardial infarction, unstable angina, cardiac death, heart failure and stroke) among the three HTN groups $(P=0.54)$.

In the normotensive group, two patients were excluded because they developed HTN based on the guidelines of the Japanese Association of Hypertension and were started on antihypertensive drug therapy. Two patients in the HTN group with good BP control were excluded because their mean BP achieved during the follow-up was higher than baseline and their BP was $\geqslant 130 / 80 \mathrm{~mm} \mathrm{Hg}$. Two patients in the HTN group with moderate BP control were excluded because their BP during follow-up was higher in one patient and lower in the other patient than the BP range at baseline that was used to classify that group. In the HTN group with poor BP control, two patients were excluded because of poor echocardiographic images due to emphysema. A total of eight patients were excluded from the final analysis. The data from 234 patients were included in the final analysis ( $88.3 \%$ follow-up rate).

The clinical characteristics of the 234 patients at baseline are shown in Table 1. There were no significant differences in age, gender, current smoking habits, diabetes mellitus, coronary artery disease and medications except for the use of $\beta$-blockers, angiotensin II receptor blockers and angiotensin-converting enzyme inhibitors among the four groups.

\section{Association between achieved BP and echocardiographic} parameters of cardiac structure and function

LV and LA structure and function in the normotensive and HTN group with good BP control were better than those in the HTN group with poor BP control, both at baseline and after 2 years (Table 2 and Figure 2). Regarding change during 2 years of follow-up, differences in the LV mass index between baseline and after 2 years in the HTN group with poor BP control were significantly higher than those in the normotensive group (Table 3). Differences in LA

Table 1 Patients' baseline characteristics

\begin{tabular}{|c|c|c|c|c|c|}
\hline & $\begin{array}{c}\text { Normotensive } \\
(\mathrm{n}=71)\end{array}$ & $\begin{array}{c}\text { Good } \\
(n=72)\end{array}$ & $\begin{array}{c}\text { Moderate } \\
(\mathrm{n}=50)\end{array}$ & $\begin{array}{c}\text { Poor } \\
(n=41)\end{array}$ & $\begin{array}{l}\mathrm{P} \text { - } \\
\text { value }\end{array}$ \\
\hline Men, $n(\%)$ & $35(49)$ & $42(58)$ & $20(40)$ & 24 (59) & 0.186 \\
\hline Age, year & $75 \pm 5$ & $74 \pm 5$ & $74 \pm 6$ & $75 \pm 5$ & 0.704 \\
\hline $\begin{array}{l}\text { Current smoking, } \\
n(\%)\end{array}$ & $16(23)$ & $17(24)$ & $12(24)$ & $11(27)$ & 0.966 \\
\hline $\begin{array}{l}\text { Diabetes mellitus, } \\
n(\%)\end{array}$ & $11(16)$ & $10(14)$ & $7(14)$ & $8(20)$ & 0.865 \\
\hline Dyslipidemia, $n(\%)$ & $30(42)$ & $35(49)$ & $25(50)$ & $17(42)$ & 0.739 \\
\hline $\begin{array}{l}\text { Coronary artery } \\
\text { disease, } n(\%)\end{array}$ & $13(18)$ & $11(15)$ & $6(12)$ & $9(22)$ & 0.636 \\
\hline ARBs or ACEIs, $n(\%)$ & - & $45(62)$ & $27(54)$ & $35(86)^{*}$ & * 0.006 \\
\hline$\beta$-Blockers, $n(\%)$ & - & $8(11)$ & $6(12)$ & $12(29)^{*}$ & * 0.027 \\
\hline $\begin{array}{l}\text { Ca channel blockers, } \\
n(\%)\end{array}$ & - & $55(76)$ & $34(68)$ & $28(68)$ & 0.508 \\
\hline Diuretics, $n(\%)$ & - & $8(11)$ & $5(10)$ & $6(15)$ & 0.776 \\
\hline $\begin{array}{l}\text { Antiplatelet } \\
\text { drugs, } n(\%)\end{array}$ & $35(44)^{*}$ & $50(69)$ & 39 (78) & $31(76)$ & 0.003 \\
\hline Statins, $n(\%)$ & $30(42)$ & $33(46)$ & $4(48)$ & $18(44)$ & 0.933 \\
\hline
\end{tabular}

Abbreviations: ACEI: angiotensin-converting enzyme inhibitor; ARB, angiotensin II receptor blocker; Ca, calcium.

Data are presented as the number (\%) of patients. ${ }^{*} P<0.05$ 
Table 2 Echocardiographic parameters at baseline and after 2 years

\begin{tabular}{|c|c|c|c|c|}
\hline$B P$ control & Normotensive & Good & Moderate & Poor \\
\hline \multicolumn{5}{|l|}{ Baseline } \\
\hline Systolic BP, mm Hg & $126 \pm 8$ & $126 \pm 3$ & $136 \pm 2^{*}, \#$ & $144 \pm 2^{*, \#, \dagger}$ \\
\hline Diastolic BP, mm Hg & $75 \pm 6$ & $75 \pm 4$ & $85 \pm 3^{*, \#}$ & $89 \pm 4^{*, \#, \dagger}$ \\
\hline LV mass index, $\mathrm{gm}^{-2}$ & $126 \pm 27$ & $134 \pm 30^{*}$ & $143 \pm 30^{*}$ & $159 \pm 41^{*, \#, \uparrow}$ \\
\hline$E / e^{\prime}$ & $8.0 \pm 1.4$ & $8.3 \pm 1.4$ & $8.8 \pm 1.6^{*}$ & $10.4 \pm 1.9^{*, \#, \dagger}$ \\
\hline LA dimension, $\mathrm{mm}$ & $39 \pm 5$ & $40 \pm 5$ & $41 \pm 6^{*}$ & $45 \pm 5^{*, \#, \dagger}$ \\
\hline Max LAVI, $\mathrm{ml} \mathrm{m}^{-2}$ & $40 \pm 10$ & $43 \pm 9$ & $54 \pm 13^{*, \#}$ & $66 \pm 18^{*, \#, \uparrow}$ \\
\hline Min LAVI, $\mathrm{ml} \mathrm{m}^{-2}$ & $23 \pm 7$ & $24 \pm 6$ & $31 \pm 9 *$ & $44 \pm 13^{*, \#, \dagger}$ \\
\hline LA total EF, \% & $46 \pm 7$ & $45 \pm 6$ & $41 \pm 7^{*, \#}$ & $33 \pm 5^{*, \#, \dagger}$ \\
\hline LA passive EF, \% & $22 \pm 8$ & $20 \pm 7$ & $17 \pm 6^{*, \#}$ & $14 \pm 5^{*, \#, \dagger}$ \\
\hline LA active $E F, \%$ & $30 \pm 8$ & $30 \pm 7$ & $28 \pm 7^{\#}$ & $21 \pm 5^{*, \#, \dagger}$ \\
\hline LA peak strain & $25 \pm 6$ & $24 \pm 6$ & $22 \pm 5^{*, \#}$ & $19 \pm 5^{*, \#, \dagger}$ \\
\hline SR systole, $\mathrm{s}^{-1}$ & $1.18 \pm 0.34$ & $1.14 \pm 0.29$ & $1.12 \pm 0.36$ & $0.97 \pm 0.37^{*, \#}$ \\
\hline SR early diastole, $\mathrm{s}^{-1}$ & $-1.02 \pm 0.31$ & $-1.00 \pm 0.23$ & $-0.85 \pm 0.31^{*, \#}$ & $-0.75 \pm 0.27^{*}, \#$ \\
\hline $\mathrm{SR}$ atrial contraction, $\mathrm{s}^{-1}$ & $-1.38 \pm 0.42$ & $-1.37 \pm 0.36$ & $-1.37 \pm 0.46$ & $-1.02 \pm 0.43^{*, \#, \dagger}$ \\
\hline \multicolumn{5}{|l|}{ After 2 years } \\
\hline Systolic BP, mm Hg & $127 \pm 7$ & $126 \pm 4$ & $135 \pm 4^{*, \#}$ & $141 \pm 3^{*, \#, \dagger}$ \\
\hline Diastolic BP, mm Hg & $77 \pm 6$ & $76 \pm 5$ & $84 \pm 4^{*}, \#$ & $86 \pm 4^{*}, \#$ \\
\hline LV mass index, $\mathrm{gm}^{-2}$ & $128 \pm 26$ & $129 \pm 29$ & $132 \pm 28$ & $149 \pm 38^{*, \#, \dagger}$ \\
\hline$E / e^{\prime}$ & $8.2 \pm 1.2$ & $8.3 \pm 1.3$ & $8.8 \pm 1.2^{*, \#}$ & $10.6 \pm 2.2^{*, \#, \dagger}$ \\
\hline LA dimension, mm & $39 \pm 5$ & $39 \pm 5$ & $42 \pm 6^{*, \#}$ & $43 \pm 5^{*}, \#$ \\
\hline Max LAVI, $\mathrm{ml} \mathrm{m}^{-2}$ & $41 \pm 13$ & $42 \pm 11$ & $53 \pm 17^{*, \#}$ & $66 \pm 17^{*, \#, \dagger}$ \\
\hline Min LAVI, $\mathrm{ml} \mathrm{m}^{-2}$ & $23 \pm 9$ & $23 \pm 8$ & $31 \pm 13^{*, \#}$ & $43 \pm 12^{*, \#, \dagger}$ \\
\hline LA total EF, \% & $46 \pm 6$ & $46 \pm 9$ & $42 \pm 8^{*}, \#$ & $35 \pm 5^{*, \#, \uparrow}$ \\
\hline LA passive EF, \% & $21 \pm 6$ & $22 \pm 9$ & $18 \pm 6^{*, \#}$ & $14 \pm 3^{*, \#, \dagger}$ \\
\hline LA active EF, \% & $32 \pm 6$ & $32 \pm 8$ & $28 \pm 7^{*, \#}$ & $22 \pm 7^{*, \#, \dagger}$ \\
\hline LA peak strain & $25 \pm 6$ & $26 \pm 5^{*}$ & $25 \pm 6^{\#}$ & $20 \pm 3^{*, \#, \dagger}$ \\
\hline SR systole, $\mathrm{s}^{-1}$ & $1.19 \pm 0.26$ & $1.30 \pm 0.36^{*}$ & $1.24 \pm 0.37$ & $0.97 \pm \pm 0.28^{*, \#, \dagger}$ \\
\hline SR early diastole, $\mathrm{s}^{-1}$ & $-1.01 \pm 0.25$ & $-1.04 \pm 0.37$ & $-0.86 \pm 0.32^{*, \#}$ & $-0.78 \pm 0.30^{*, \#}$ \\
\hline SR atrial contraction, $\mathrm{s}^{-1}$ & $-1.43 \pm 0.39$ & $-1.52 \pm 0.40$ & $-1.41 \pm 0.35$ & $-1.10 \pm 0.32^{*, \#, \dagger}$ \\
\hline
\end{tabular}

Abbreviations: BP, blood pressure; E/e', ratio of early diastolic transmitral inflow velocity to annular tissue velocity; EF, emptying function; LA, left atrial; LAVI, left atrial volume index; LV, left ventricular; Max, maximum; Min, minimum; SR, strain rate.

${ }^{*} P<0.05$ vs normal, ${ }^{*} P<0.05$ vs good, ${ }^{\dagger} P<0.05$ vs moderate.

function between baseline and after 2 years were not significant when comparing the HTN group with poor BP control with the normotensive control group and the HTN group with good BP control.

\section{Development of new-onset AF}

During a follow-up period of 24 months, 14 out of $234(6.0 \%)$ subjects developed ECG-confirmed new-onset AF. All new-onset AF cases were of paroxysmal AF. Two patients in the normotensive group, one in the HTN group with good BP control, three in the HTN group with moderate BP control and eight in the HTN group with poor BP control developed new-onset AF. The incidence of new-onset AF was significantly higher in the HTN group with poor BP control compared with the other HTN groups. The Kaplan-Meier curves in Figure 3 show the differences in the cumulative survival of new-onset AF between the HTN group with poor BP control and the other three groups combined. The HTN group with poor BP control had a significantly higher incidence of new-onset AF than the other three groups (hazard ratio: 7.015; 95\% confidence interval: 2.433-20.22; $P<0.001)$.

Including the 234 patients in all four groups, patients with newonset AF had a larger LA volume and reduced LA function compared with patients without new-onset AF (Table 4). We performed multivariate Cox regression analysis using the HTN group with poor BP control and age as a conventional variable to elucidate the independent predictors of new-onset AF in all 234 patients. In model 1 , multivariate Cox regression analysis was performed using parameters with a $P$-value of $<0.1$ in univariate analysis. That is, we included the difference in maximum LAV index and LA active EF between baseline and follow-up. Because our previous study showed that LA active EF was an independent predictor of new-onset $A F^{8} \mathrm{LA}$ active EF at baseline was included in model 2 (in addition to the HTN with poor BP control and age). Because $\mathrm{E} / \mathrm{e}^{\prime}$ was an important parameter of diastolic function, $\mathrm{E} / \mathrm{e}^{\prime}$ was also included in model 2 . In model 1, which included the difference in echocardiographic parameters between baseline and follow-up, the HTN group with poor BP control and age were independent predictors of new-onset AF in all 234 patients (Table 5). In model 2, which included only parameters at baseline, $\mathrm{E} / \mathrm{e}^{\prime}$ was an independent predictor of newonset AF.

\section{DISCUSSION}

The present prospective study demonstrated that LV mass index, LV diastolic function and LA structure and function in the HTN group 
LA total EF (\%)

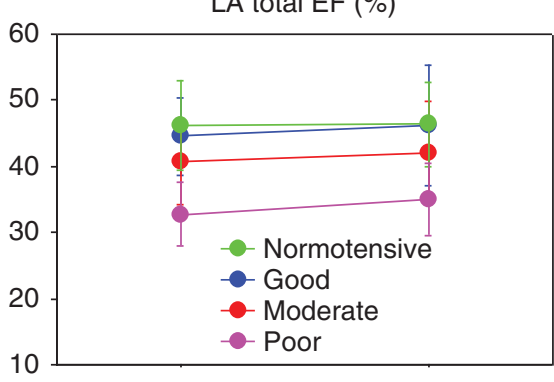

Baseline Follow-up

SR during systole $\left(\mathrm{S}^{-1}\right)$

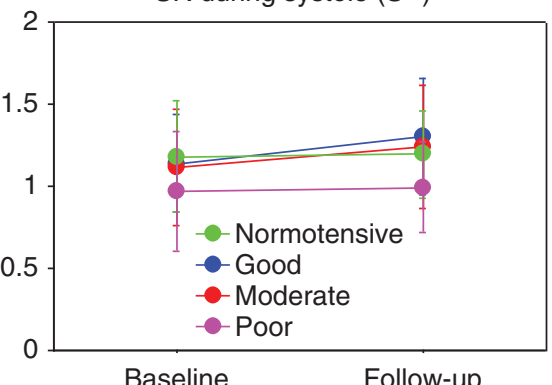

E/e

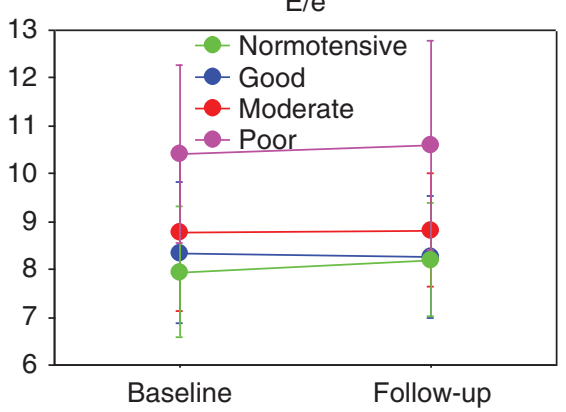

LA passive EF (\%)

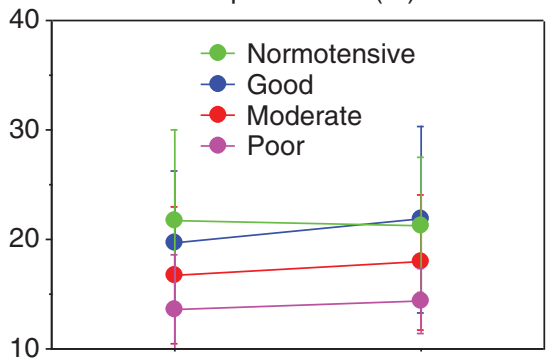

Baseline

Follow-up

SR during early diastole $\left(\mathrm{S}^{-1}\right)$

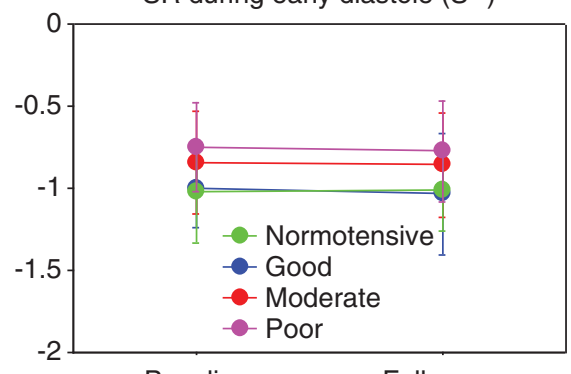

Baseline

Follow-up

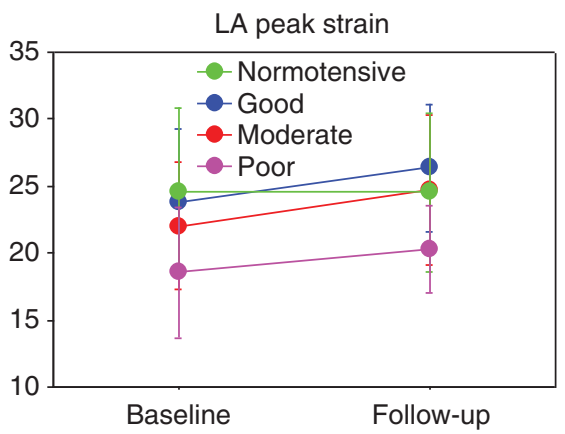

LA active EF (\%)

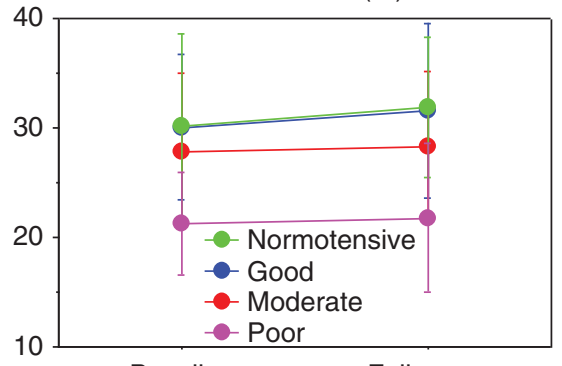

Follow-up

SR during atrial contraction $\left(\mathrm{S}^{-1}\right)$
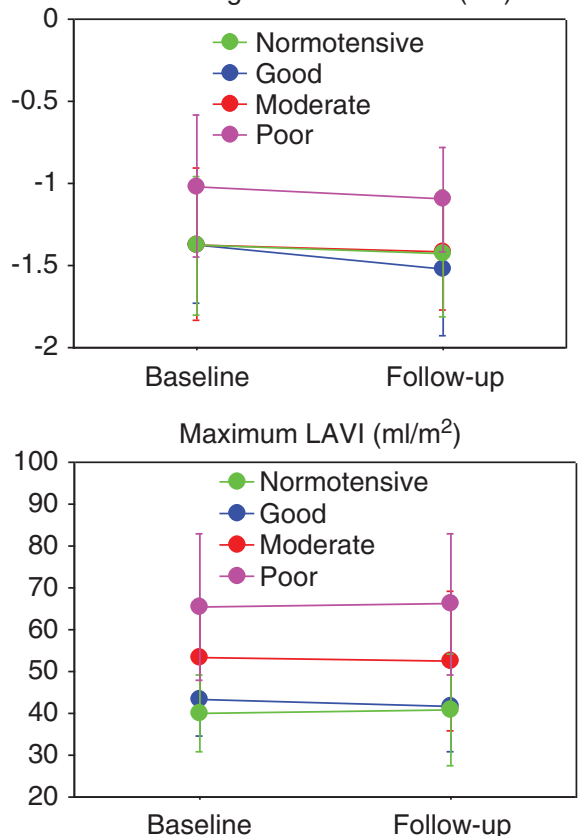

Figure 2 Comparison of global and phasic left atrial function among the four groups at baseline and after 2 years. EF, emptying fraction; LA, left atrial; LAVI, left atrial volume index; SR, strain rate.

Table 3 Differences in echocardiographic parameters between baseline and after 2 years

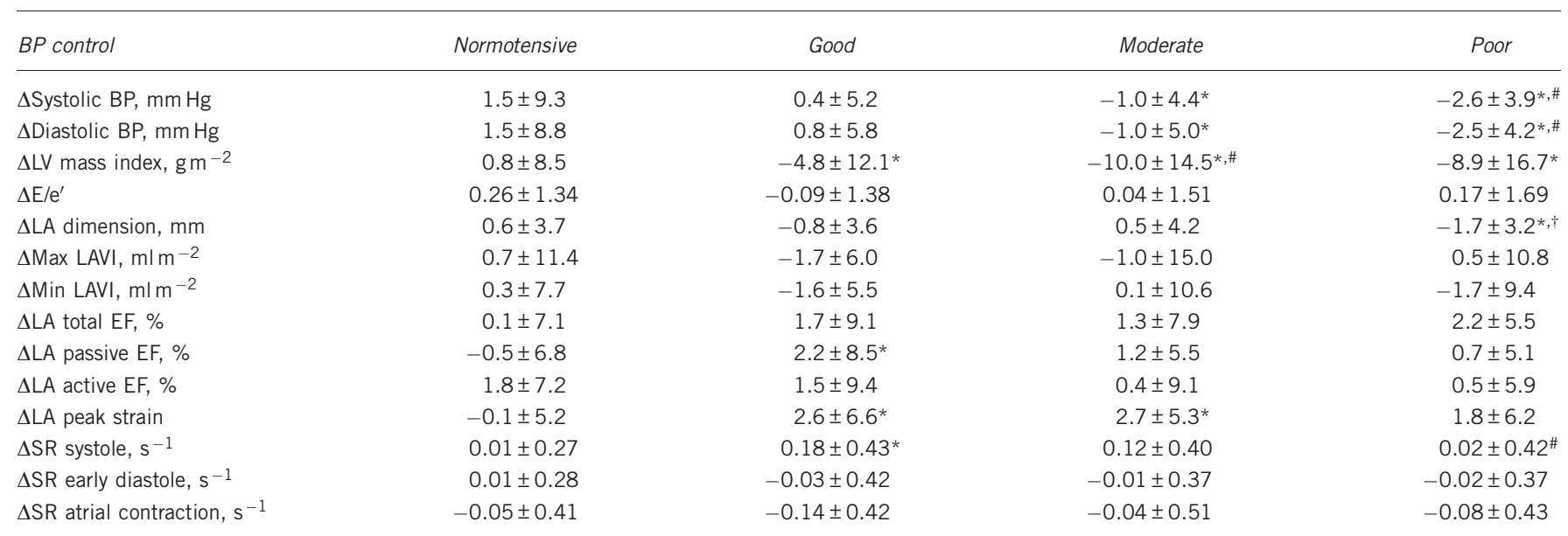

Abbreviations: $\mathrm{BP}$, blood pressure; E/e', ratio of early diastolic transmitral inflow velocity to annular tissue velocity; EF, emptying function; LA, left atrial; LAVI, left atrial volume index; LV, left ventricular; Max, maximum; Min, minimum; SR, strain rate.

${ }^{*} P<0.05$ vs normal, ${ }^{\#} P<0.05$ vs good, ${ }^{\dagger} P<0.05$ vs moderate. 


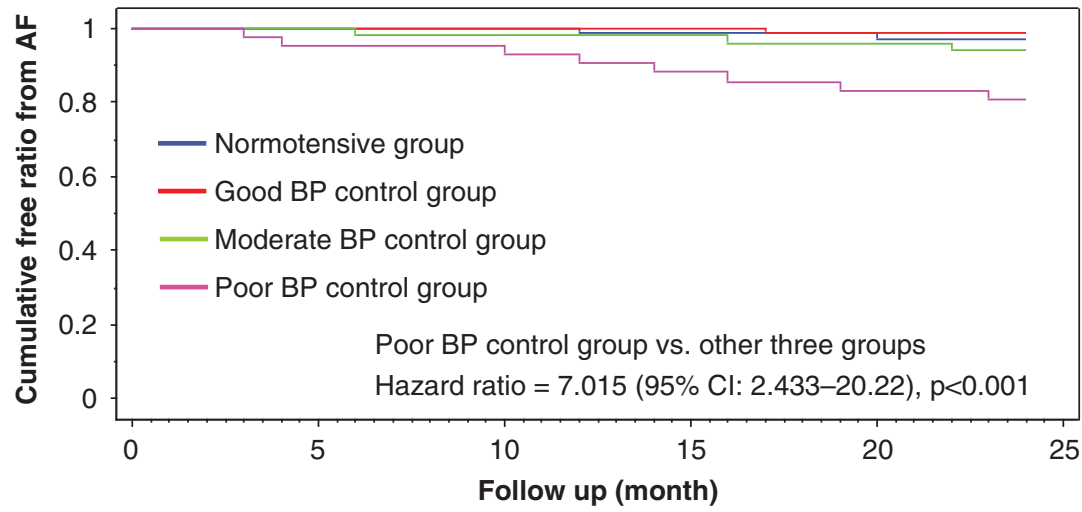

Figure 3 Kaplan-Meier curves showing cumulative survival free from atrial fibrillation (AF) in the four groups. Hazard ratios were evaluated between the hypertension (HTN) group with poor blood pressure (BP) control and the other three groups combined.

Table 4 Patient clinical characteristics and echocardiographic parameters at baseline and differences between baseline and after 2 years between non-AF and AF groups

\begin{tabular}{|c|c|c|c|}
\hline & $\begin{array}{c}\text { Non-AF group } \\
(n=220)\end{array}$ & $\begin{array}{l}\text { AF group } \\
(\mathrm{n}=14)\end{array}$ & P-value \\
\hline Sex (female/male) & 109/111 & $5 / 9$ & 0.314 \\
\hline Age, years & $74.5 \pm 4.9$ & $78.5 \pm 5.3$ & 0.004 \\
\hline Diabetes mellitus, $n$ (\%) & $33(15)$ & $3(15)$ & 0.518 \\
\hline Dyslipidemia, $n(\%)$ & $103(47)$ & $4(46)$ & 0.184 \\
\hline Current smoking, $n(\%)$ & $49(22)$ & $7(50)$ & 0.018 \\
\hline Coronary artery disease, $n(\%)$ & $37(17)$ & $2(14)$ & 0.805 \\
\hline Systolic BP, mm Hg & $131 \pm 9$ & $137 \pm 10$ & 0.007 \\
\hline Diastolic BP, $\mathrm{mm} \mathrm{Hg}$ & $79 \pm 7$ & $83 \pm 9$ & 0.084 \\
\hline LDL cholesterol, mg dl ${ }^{-1}$ & $99 \pm 18$ & $97 \pm 20$ & 0.692 \\
\hline HDL cholesterol, $\mathrm{mg} \mathrm{dl}^{-1}$ & $56 \pm 13$ & $55 \pm 11$ & 0.493 \\
\hline \multicolumn{4}{|l|}{ Baseline } \\
\hline LV ejection fraction, $\%$ & $67 \pm 7$ & $65 \pm 8$ & 0.269 \\
\hline LV mass index, $\mathrm{g} \mathrm{m}^{-2}$ & $138 \pm 33$ & $153 \pm 45$ & 0.092 \\
\hline LA dimension, mm & $40 \pm 5$ & $46 \pm 6$ & 0.001 \\
\hline $\mathrm{E} / \mathrm{e}^{\prime}$ & $8.6 \pm 1.8$ & $10.2 \pm 1.3$ & $<0.001$ \\
\hline Max LAVI, $\mathrm{ml} \mathrm{m}^{-2}$ & $48 \pm 15$ & $60 \pm 15$ & 0.003 \\
\hline Min LAVI, $\mathrm{ml} \mathrm{m}^{-2}$ & $28 \pm 11$ & $39 \pm 10$ & $<0.001$ \\
\hline LA total EF, \% & $43 \pm 8$ & $35 \pm 8$ & 0.001 \\
\hline LA passive $E F, \%$ & $19 \pm 7$ & $15 \pm 8$ & 0.067 \\
\hline LA active $E F, \%$ & $29 \pm 11$ & $22 \pm 6$ & $<0.001$ \\
\hline LA peak strain & $23 \pm 6$ & $18 \pm 5$ & 0.001 \\
\hline SR systole, $\mathrm{s}^{-1}$ & $1.1 \pm 0.3$ & $0.9 \pm 0.2$ & 0.011 \\
\hline SR early diastole, $\mathrm{S}^{-1}$ & $-1.0 \pm 0.3$ & $-0.7 \pm 0.2$ & 0.003 \\
\hline $\mathrm{SR}$ atrial contraction, $\mathrm{s}^{-1}$ & $-1.3 \pm 0.4$ & $-1.0 \pm 0.3$ & $<0.001$ \\
\hline \multicolumn{4}{|c|}{ Differences between baseline and after 2 years } \\
\hline$\Delta \mathrm{LA}$ dimension, $\mathrm{mm}$ & $-0.30 \pm 3.70$ & $-1.86 \pm 4.26$ & 0.13 \\
\hline$\Delta \mathrm{E} / \mathrm{e}^{\prime}$ & $0.09 \pm 1.42$ & $0.11 \pm 1.97$ & 0.96 \\
\hline$\Delta \mathrm{Max}$ LAVI, $\mathrm{mlm}^{-2}$ & $-0.96 \pm 9.66$ & $7.86 \pm 21.81$ & 0.003 \\
\hline$\Delta \mathrm{LA}$ total $\mathrm{EF}, \%$ & $1.30 \pm 7.64$ & $0.00 \pm 9.17$ & 0.54 \\
\hline$\Delta \mathrm{LA}$ passive $\mathrm{EF}, \%$ & $0.94 \pm 6.98$ & $0.43 \pm 5.36$ & 0.79 \\
\hline$\Delta \mathrm{LA}$ active $\mathrm{EF}, \%$ & $1.45 \pm 8.13$ & $-2.71 \pm 7.63$ & 0.064 \\
\hline$\Delta$ SR systole, $\mathrm{s}^{-1}$ & $0.09 \pm 0.39$ & $0.06 \pm 0.33$ & 0.81 \\
\hline$\Delta S R$ early diastole, $\mathrm{S}^{-1}$ & $-0.01 \pm 0.37$ & $-0.09 \pm 0.22$ & 0.40 \\
\hline$\Delta S R$ atrial contraction, $\mathrm{s}^{-1}$ & $-0.09 \pm 0.44$ & $0.09 \pm 0.28$ & 0.14 \\
\hline
\end{tabular}

Abbreviations: $\mathrm{AF}$, atrial fibrillation; $\mathrm{BP}$, blood pressure; $\mathrm{E} / \mathrm{e}^{\prime}$, ratio of early diastolic transmitral inflow velocity to annular tissue velocity; $E F$, emptying function; $H D L$, high-density lipoprotein; LA, left atrial; LAVI, left atrial volume index; LDL, low-density lipoprotein; LV, left ventricular; Max, maximum; Min, minimum; SR, strain rate.
Table 5 Multivariate Cox regression analysis for the independent predictors of new-onset AF

\begin{tabular}{lrrr}
\hline Variables & Hazard ratio & $95 \% \mathrm{Cl}$ & P-value \\
\hline Model 1 & & & \\
HTN with poor BP control & 7.447 & $2.522-21.98$ & $<0.001$ \\
Age & 1.117 & $1.007-1.239$ & 0.036 \\
$\Delta$ Max LAVI (change over 2 years) & 0.988 & $0.953-1.026$ & 0.558 \\
$\Delta$ LA active EF (change over 2 years) & 1.025 & $0.953-1.140$ & 0.496 \\
Model 2 & & & \\
HTN with poor BP control & 3.080 & $0.821-11.56$ & 0.095 \\
Age & 1.090 & $0.976-1.217$ & 0.126 \\
E/e' (baseline) & 1.331 & $1.077-1.645$ & 0.008 \\
LA active EF (baseline) & 0.967 & $0.887-1.055$ & 0.454 \\
\end{tabular}

Abbreviations: $\mathrm{AF}$, atrial fibrillation; $\mathrm{BP}$, blood pressure; $\mathrm{Cl}$, confidence interval; $\mathrm{E} / \mathrm{e}^{\prime}$, ratio of early diastolic transmitral inflow velocity to annular tissue velocity; $E F$, emptying function; HTN, hypertension; LA, left atrial; LAVI, left atrial volume index; Max, maximum.

with poor BP control were more impaired than in normotensive patients, both at baseline and follow-up. These parameters, except for LV mass and LA dimension, did not change during 2 years of followup in the HTN group with poor BP control. The incidence of newonset AF depended on a constant level of BP control during longterm follow-up (4 years) rather than the change of cardiac structure and function during short-term follow-up (2 years). Poor BP control increased the incidence of new-onset AF in elderly patients with HTN.

BP control for the prevention of AF in elderly patients with HTN We recently reported that pitavastatin therapy prevented new-onset AF in 220 elderly patients with HTN (age $75 \pm 5$ years). ${ }^{9}$ The incidence of new-onset AF was relatively lower (HTN without statin group: $13.6 \% / 2$ years and HTN with statin group: $4.5 \% / 2$ years) than expected because the BP levels were adequately controlled $(133 \pm 6 / 79 \pm 6 \mathrm{mmHg}) .{ }^{9}$ The general recommended BP goal in uncomplicated elderly patients with HTN is $<140 / 90 \mathrm{~mm} \mathrm{Hg}$, which is based on expert opinion rather than on data from randomized controlled trials. ${ }^{14,15}$ However, the ACCORD study that compared the effect between intensive BP control (target systolic $\mathrm{BP}<120 \mathrm{~mm} \mathrm{Hg}$ ) 
and usual BP control (target systolic $\mathrm{BP}<140 \mathrm{~mm} \mathrm{Hg}$ ) on the cardiovascular events in HTN patients with diabetes mellitus found no significant difference between the two groups. ${ }^{16}$ Although some clinic-and population-based survey data continue to suggest that the lower the BP levels, the lower the cardiovascular event rate even in elderly patients, ${ }^{17,18}$ the VALISH study demonstrated that strict BP control $(136.6 / 74.8 \mathrm{~mm} \mathrm{Hg})$ was not superior to moderate BP control $(142.0 / 76.5 \mathrm{~mm} \mathrm{Hg})$ in reducing cardiovascular mortality and morbidity in elderly patients (mean age 76.1 years) during 3 years of follow-up. ${ }^{19}$ The JATOS study also demonstrated that the incidence of cardiovascular disease and renal failure was similar between the strict treatment group $(135.9 / 74.8 \mathrm{~mm} \mathrm{Hg})$ and mild treatment group $(145.6 / 78.1 \mathrm{~mm} \mathrm{Hg})$ during 2 years of followup. ${ }^{20}$ In contrast, the present study showed that poor BP control $(144 \pm 2 / 89 \pm 4 \mathrm{~mm} \mathrm{Hg})$ increased the incidence of new-onset AF, indicating that more strict BP control may be even more necessary in the prevention of AF than in the prevention of other types of cardiovascular disease.

\section{Importance of long-term $\mathrm{BP}$ control for the prevention of $\mathrm{AF}$}

There was an intriguing finding in the present study. In the elderly patients with HTN, baseline LA structure and function as well as changes in LA structure and function over 2 years were not related to the incidence of new-onset AF, whereas LA structure and function were more impaired in the HTN group with poor BP control compared with the other three groups. The incidence of new-onset $\mathrm{AF}$ was associated with the BP level over 4 years (2 years before enrollment and 2 years after enrollment). In our previous study that included 580 patients from the general population (56\% with HTN, aged $64 \pm 17$ years), we showed that LA active EF (booster pump function) at baseline independently predicted the risk of new-onset $\mathrm{AF}^{7}$ Reduced LA active EF independently predicts the risk of newonset AF, suggesting a stronger association between LA functional remodeling and new-onset AF than between LA size and new-onset AF. However, this relationship was not observed in the present study in elderly patients ( $70 \%$ with HTN, aged $75 \pm 5$ years). That is, the incidence of new-onset AF depended on the degree of BP control during 4 years rather than changes in LA structure and function over 2 years. This finding suggests that long-term BP control in HTN ( $\mathrm{BP}<140 / 90 \mathrm{~mm} \mathrm{Hg}$ ) is important to prevent new-onset AF in elderly patients.

In multivariate Cox regression analysis that included only parameters at baseline, $\mathrm{E} / \mathrm{e}^{\prime}$ at baseline was an independent predictor of new-onset AF. Although $\mathrm{e}^{\prime}$ represents regional tissue velocity, $\mathrm{e}^{\prime}$ has been thought to reflect LV relaxation and has a correlation with pulmonary capillary wedge pressure. ${ }^{21}$ Similarly, the E wave is also affected by loading conditions. When afterload increases, the $\mathrm{E}$ wave decreases and when preload increases, the $\mathrm{E}$ wave increases. ${ }^{22}$ The ratio of the peak early transmitral flow velocity (E) to the peak early myocardial tissue velocity $\left(\mathrm{E} / \mathrm{e}^{\prime}\right)$ was proposed to estimate LV filling pressure. ${ }^{21}$ HTN causes pressure overload in the left ventricle. It was probable that $\mathrm{E} / \mathrm{e}^{\prime}$ was an independent predictor of new-onset $\mathrm{AF}$ in elderly patients with $\mathrm{HTN}$ because $\mathrm{E} / \mathrm{e}^{\prime}$ reflected the $\mathrm{LV}$ filling pressure that reflected the loading conditions of the left atrium of the patients.

Previous studies have reported that treatment with angiotensinconverting enzyme inhibitors or angiotensin II receptor blockers can delay the progression of paroxysmal $\mathrm{AF}$ to chronic $\mathrm{AF}^{23-25}$ In the present study, despite the frequent prescription of angiotensin II receptor blockers or angiotensin-converting enzyme inhibitors in the HTN group with poor BP control, the incidence of new-onset AF was the highest in this group compared with the other three groups. This finding suggests that the upstream inhibition of the renninangiotensin system was insufficient to prevent new-onset AF. The recent J-RHYTHM study demonstrated a similar decrease in AF frequency over 12 months in the patients treated with calcium channel blockers and angiotensin II receptor blockers. ${ }^{26}$ However, there was no control group in either that study or the present study. Thus, we could not determine if angiotensin II receptor blockers or angiotensin-converting enzyme inhibitors could reduce the incidences of $\mathrm{AF}$ in the present study.

\section{Study limitations}

There are several limitations of the present study. First, only patients whose BP levels were constant during follow-up were included in the present study. In clinical practice, however, BP levels are not always constant. Patients whose BP levels are not constant might have higher rates of new-onset AF. Therefore, exclusion of patients with unstable HTN was a major limitation of the present study. In addition, patients with BP that did not change over 2 years were enrolled in the present study, and this resulted in a patient selection bias. Second, a relatively small number of the patients were enrolled and only 14 of 234 patients developed new-onset AF. Thus, the study may have been underpowered to definitively determine the relationship between the incidence of new-onset $\mathrm{AF}$ and cardiac structure and function particularly in the multivariate Cox regression analysis. A study in a larger population is needed to define the appropriate BP treatment thresholds and goals for the prevention of new-onset AF. Third, the number of incident AF cases may have been underestimated because some patients with AF had no symptoms and only AF episodes that were confirmed by ECG or Holter ECG were considered an end point. However, this limitation could be applied to most of the previous studies that included AF as an end point. Fourth, patients in the HTN group with poor BP control had greater use of $\beta$-blockers, angiotensin II receptor blockers or angiotensin-converting enzyme inhibitors at the time of enrollment. This significant difference may have influenced the risk of new onset of AF. Finally, VVI is based on manual tracing and represents a two-dimensional measurement. Three-dimensional speckle tracking echocardiography is the latest technique and is now available to assess LA structure and function, including LA volume and SR without any assumptions of LA geometry. ${ }^{27}$ Reassessment of the predictive values and cutoffs in the present study by three-dimensional speckle tracking echocardiography is needed in the future.

\section{CONCLUSIONS}

The incidence of new-onset AF depended on the long-term level of $\mathrm{BP}$ control rather than short-term changes in LA structure and function. Poor BP control increased the risk of new-onset AF in elderly patients with HTN.

\section{CONFLICT OF INTEREST}

The authors declare no conflict of interest.

\section{ACKNOWLEDGEMENTS}

We gratefully acknowledge the contribution of Ms Tomomi Endo and Mr Satoshi Yamajima for ultrasound investigation and Ms Ritsuko Tanaka and Mr Kazuyuki Tsujimoto for preparation of the manuscript. 
1 Kannel WB, Wolf PA, Benjamin EJ, Levy D. Prevalence, incidence, prognosis, and predisposing conditions for atrial fibrillation: population-based estimates. Am J Cardiol 1998; 82: 2N-9N.

2 Benjamin EJ, Levy D, Vaziri SM, D’Agostino RB, Belanger AJ, Wolf PA. Independent risk factors for arterial fibrillation in a population-based cohort. JAMA 1994; 271: 840-844.

3 Senoo K, Suzuki S, Sagara K, Otsuka T, Matsuno S, Funada R, Uejima T, Oikawa Y, Yajima J, Koike A, Nagashima K, Kirigaya H, Sawada H, Aizawa T, Yamashita T. Distribution of first-detected atrial fibrillation patients without structural heart diseases in symptom classifications. Circ J 2012; 76: 1020-1023.

4 Zile MR, Brutsaert DL. New concepts in diastolic dysfunction and diastolic heart failure: part 1: diagnosis, prognosis, and measurement of diastolic dysfunction. Circulation 2002; 105: 1387-1393.

5 Goto S, Ikeda Y, Shimada K, Uchiyama S, Origasa H, Kobayashi HThe J-TRACE investigators. One-year cardiovascular event rates in Japanese outpatients with myocardial infarction, stroke, and atrial fibrillation. Circ J 2011; 75: 2598-2604.

6 Verdecchia P, Reboldi G, Gattobigio R, Bentivogio M, Bolgioni C, Angeli F, Carluccio E, Sardone MG, Porcellati C. Atrial fibrillation in hypertension: predictors and outcome. Hypertension 2003; 41: 218-223.

7 Hirose T, Kawasaki M, Tanaka R, Ono K, Watanabe T, Iwama M, Noda T, Watanabe S, Takemura G, Minatoguchi S. Left atrial function assessed by speckle tracking echocardiography as a predictor of new-onset non-valvular atrial fibrillation: results from a prospective study in 580 adults. Eur Heart J Cardiovasc Imaging 2012; 13 243-250.

8 Ogawa K, Hozumi T, Sugioka K, Iwata S, Otsuka R, Takagi Y, Yoshitani H, Yoshiyama M, Yoshikawa J. Automated assessment of left atrial function from time-left atrial volume curves using a novel speckle tracking imaging method. J Am Soc Echocardiogr 2009; 22: 63-69.

9 Warita S, Kawasaki M, Tanaka R, Ono K, Kojima T, Hirose T, Iwama M, Watanabe T, Nishigaki K, Takemura G, Noda T, Watanabe S, Minatoguchi S. Effects of pitavastatin on cardiac structure and function and on the prevention of atrial fibrillation in elderly hypertensive patients: a prospective study of two-years follow-up. Circ J 2012; 76: 2755-2762.

10 Rahimi K, Emberson J, McGale P, Majoni W, Merhi A, Asselbergs FW, Krane V, Macfarlane PW. PROSPER Executive. Effect of statins on atrial fibrillation: collaborative meta-analysis of published and unpublished evidence from randomized controlled trials. BMJ 2011; 342: d1250.

11 Faunchier L, Pierre B, de Labriolle A, Grimard C, Zannad N, Babuty D. Antiarrhythmic effect of statin therapy and atrial fibrillation a meta-analysis of randomized controlled trials. J Am Coll Cardiol 2008; 51: 828-835.

12 Japanese Society of Hypertension Guidelines Subcommittee for the Management of Hypertension. Guideline for the management of hypertension for general practitioners. Hypertens Res 2001; 24: 613-634.

13 Lang RM, Bierig M, Devereux RB, Flachskampf FA, Foster E, Pellikka PA, Picard MH, Roman MJ, Seward J, Shanewise JS, Solomon SD, Spencer KT, Sutton MS, Stewart WJ, Chamber Quantification Writing Group American Society of Echocardiography's Guidelines and Standards Committee European Association of Echocardiography. Recommendation for chamber quantification: a report from the American Society of Echocardiography's Guidelines and Standards Committee and the Chamber Quantification Writing Group, developed in conjunction with the European Association of Echocardiography, a branch of the European Society of Cardiology. J Am Soc Echocardiogr 2005; 18: 1440-1463.

14 World Health Organization, International Society of Hypertension Writing Group. 2003 World Health Organization (WHO)/International Society of Hypertension
(ISH) statement on management of hypertension. J Hypertens 2003; 21 1983-1992.

15 Aronow WS, Fleg JL, Pepine CJ, Artinian NT, Bakris G, Brown AS, Ferdinand KC Forciea MA, Frishman WH, Jaigobin C, Kostis JB, Mancia G, Oparil S, Ortiz E, Reisin E, Rich MW, Schocken DD, Weber MA, Wesley DJ, Harrington RAACCF Task Force. ACCF/ AHA 2011 expert consensus document on hypertension in the elderly: a report of the American College of Cardiology Foundation Task Force on Clinical Expert Consensus Documents. Circulation 2011; 123: 2434-2506.

16 The ACCORD study group. Effect of intensive blood-pressure control in type 2 diabetes mellitus. N Engl J Med 2010; 362: 1575-1585.

17 Lewington S, Clarke R, Qizilbash N, Peto R, Collins R. Age-specific relevance of usual blood pressure to vascular mortality: a meta-analysis of individual data for one million adults in 61 prospective studies. Prospective studies Collaboration. Lancet 2002; 360: 1903-1913.

18 Vasan RS, Larson MG, Leip EP, Evans JC, O'Donnell CJ, Kannel WB, Levy D. Impact of high normal blood pressure on the risk of cardiovascular disease. N Eng J Med 2001; 345: 1291-1297.

19 Ogihara T, Saruta T, Rakugi H, Matsuoka H, Shimamoto K, Shimada K, Imai Y, Kikuchi K, Ito S, Edo T, Kimura G, Imaizumi T, Takishita S, Ueshima H. For the Valsartan in Elderly Isolated Systolic Hypertension Study Group. Target blood pressure for treatment of isolated systolic hypertension in the elderly: valsartan in elderly isolated systolic hypertension study. Hypertension 2010; 56: 196-202.

20 JATOS study group. Principal results of the Japanese trial to assess optimal systolic blood pressure in elderly hypertensive patients (JATOS). Hypertens Res 2008; 31: 2115-2127.

21 Nagueh SF, Middleton KJ, Kopelen HA, Zoghbi WA, Quinones MA. Doppler tissue imaging: a noninvasive technique for evaluation of left ventricular relaxation and estimation of filling pressures. J Am Coll Cardiology 1997; 30: 1527-1533.

22 Stoddard MF, Pearson AC, Kern MJ, Ratcliff J, Mrosek DG, Labovitz AJ. Influence of alteration in preload on the pattern of left ventricular diastolic filling as assessed by Doppler echocardiography in humans. Circulation 1989; 79: 1226-1236.

23 Vermes E, Tardif JC, Bourassa MG, Racine N, Levesque S, White M, Guerra PG, Ducharme A. Enalapril decreases the incidence of atrial fibrillation in patients with left ventricular dysfunction: insight from the Studies of Left Ventricular Dysfunction (SOLVD) trials. Circulation 2003; 107: 2926-2931.

24 Wachtell K, Lehto M, Gerdts E, Olsen MH, Hornestam B, Dahlöf B, Ibsen H, Julius S, Kjeldsen SE, Lindholm LH, Nieminen MS, Devereux RB. Angiotensin II receptor blockade reduces new-onset atrial fibrillation and subsequent stroke complication to atenolol. J Am Coll Cardiol 2005; 45: 712-719.

25 Madrid AH, Bueno MG, Rebollo JM, Marín I, Peña G, Bernal E, Rodriguez A, Cano L, Cano JM, Cabeza P, Moro C. Use of irbesartan to maintain sinus rhythm in patients with long-lasting persistent atrial fibrillation. A prospective and randomized study. Circulation 2002; 106: 331-336.

26 Yamashita T, Inoue H, Okumura K, Kodama I, Aizawa Y, Atarashi H, Ohe T, Ohtsu H, Kato T, Kamakura S, Kumagai K, Kurachi Y, Koretsune Y, Saikawa T, Sakurai M, Sato T, Sugi K, Nakaya H, Hirai M, Hirayama A, Fukatani M, Mitamura H, Yamazaki T, Watanabe E, Ogawa SJ-RHYTHM II Investigators. Randomized trial of angiotensin IIreceptor blocker vs. dihydropiridine calcium channel blocker in the treatment of paroxysmal atrial fibrillation with hypertension (J-RHYTHM II study). Europace 2011; 4: 473-479.

27 Pérez de Isla L, Balcones DV, Fernández-Golfín C, Marcos-Alberca P, Almería C Rodrigo JL, Macaya C, Zamorano J. Three-dimensional-wall motion tracking: a new and faster tool for myocardial strain assessment: comparison with two-dimensional-wall motion tracking. J Am Soc Echocardiogr 2009; 22: 325-330. 